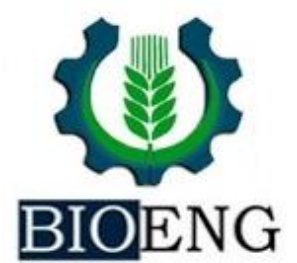

\title{
CARACTERÍSTICAS FÍSICAS E GERMINATIVAS DE SEMENTES DE Trichilia claussenii C.DC. PARA A REGIÃO DO MÉDIO ALTO URUGUAI - RS
}

\author{
C. R. B. Maffra
}

UFSM - Universidade Federal de Santa Maria, Santa Maria, RS, Brasil.

Article history: Received 27 February 2019; Received in revised form 11 March 2019; Accepted 21 March 2019; Available online 30 March 2019.

\section{RESUMO}

O conhecimento dos aspectos germinativos de espécies nativas da Floresta Estacional Decidual é importante para impulsionar programas de recuperação de fragmentos florestais nesta região fitoecológica. Neste sentido, o presente trabalho teve por objetivo determinar os aspectos físicos e germinativos de sementes de Trichilia claussenii C.DC, uma espécie importante que predomina em muitos fragmentos da região do Médio Alto Uruguai-RS. Para a determinação do peso de mil sementes foram utilizadas oito repetições de 100 sementes cada e calculado o coeficiente de variação. Para o teor de umidade utilizou-se 4 repetições de 25 sementes, as quais foram submetidas à secagem em estufa a $105^{\circ} \mathrm{C} \pm 3^{\circ} \mathrm{C}$ por 24 horas. Para a determinação do Índice de Velocidade de Germinação (IVG) e da Germinação Final (GF) utilizou-se 16 repetições de 25 sementes, colocadas em caixas plásticas gerbox com vermiculita umedecida por água destilada e acondicionadas em câmara de germinação (BOD). $\mathrm{O}$ peso de mil sementes foi de $851 \mathrm{~g}$ (1.175 sementes $/ \mathrm{kg}$ e $\mathrm{CV}=1,7 \%)$ com umidade de $39,2 \%$. O IVG encontrado foi de 2,78 e a germinação final de $73,28 \%$. Essas informações são úteis para a silvicultura da espécie.

Palavras-chave: Silvicultura, Recuperação de Áreas Degradadas, Floresta Estacional Decidual

\section{PHYSICAL AND GERMINATIVE CHARACTERISTICS OF Trichilia claussenii C.DC. FOR THE REGION OF THE HIGH MEDIUM URUGUAY - RS}

\begin{abstract}
The knowledge of the germinative aspects of native species of the Deciduous Forest is important to promote recovery programs in forest fragments in this phytoecological region. In this sense, the present study aimed to determine the physical and germinative aspects of seeds of Trichilia claussenii C.DC. For the determination of the weight of one thousand seeds, eight repetitions of 100 seeds each were used and the coefficient of variation was calculated. For the moisture content, 4 repetition of 25 seeds were used, which were dried in an oven at 105 ${ }^{\circ} \mathrm{C} \pm 3^{\circ} \mathrm{C}$ for 24 hours. Sixteen replicates of 25 seeds were placed in gerbox plastic boxes with vermiculite, moistened with distilled water and placed in a germination chamber (BOD), to determine the rate of germination velocity (GV) and final germination (FG). The weight of one thousand seeds was $851 \mathrm{~g}(1,175$ seeds $/ \mathrm{kg}$ and $\mathrm{CV}=1.7 \%)$ with humidity of $39.2 \%$. The $\mathrm{GV}$ found was 2.8 and the final germination was $73.3 \%$. This information is useful for the species' silviculture.
\end{abstract}

Keywords: Silviculture, Recovery of Degraded Areas, Deciduous Forest

\footnotetext{
charles.mafra@hotmail.com
} 


\section{INTRODUÇÃO}

A Trichilia claussenii C.DC., conhecida popularmente como catiguávermelho, pertence a uma família vegetal com várias espécies consideradas importantes e nobres no estado do Rio Grande do Sul, a das meliáceas, que é constituída por aproximadamente 750 espécies (ARALDI et al., 2006).

O catiguá-vermelho desenvolve-se como arvoreta característica e exclusiva da Floresta Ombrófila Densa, Floresta Estacional Semidecidual e Floresta Estacional Decidual nos Estados brasileiros do Rio Grande do Sul e Santa Catarina, nos quais pode medir de 6 a $12 \mathrm{~m}$ de altura e de 20 a $30 \mathrm{~cm}$ de diâmetro (ARALDI et al., 2006; REITZ, 1984). As suas plantas podem ser monóicas ou dióicas, com folhagem densa, de cor verdeescura ou verde-oliva de folíolos compridos, lanceolados e com nervuras muito evidentes (GIRARDI, 1975). Tipicamente o tronco dessa espécie pode ser cilíndrico, reto ou levemente tortuoso com 4 a 5 m de comprimento aproveitável, apresentando madeira vermelha compacta, sólida, flexível e bastante resistente às intempéries, pouco dura, fácil de rachar, sendo própria para obras externas, marcenarias, carroçaria, torno, carpintaria e de excelente lenha; seu peso específico é de 0,60 a $0,64 \mathrm{~g} / \mathrm{cm}^{3}$ (REITZ, 1984; CORREIA, 1940).

Conforme Longhi (1995), o catiguávermelho é uma espécie florestal secundário tardia que constitui-se às vezes, numa das mais características espécies dos grupos ecológicos de sucessão, podendo ocorrer em todos os estratos arbóreos, sendo de fácil multiplicação e regeneração

\section{MATERIAL E MÉTODOS}

O experimento foi conduzido no Laboratório de Silvicultura do curso de Engenharia Florestal da Universidade Federal de Santa Maria, Campus de Frederico Westphalen - RS, Brasil.

Os frutos de catiguá-vermelho (Trichilia claussenii) foram coletados em natural. Assim, por apresentar características silviculturais e ecológicas consideravelmente interessantes, o catiguávermelho pode ser indicado para a reabilitação de ecossistemas florestais que sofreram cortes seletivos de árvores, para plantios em clareiras de matas ou ainda para plantios destinados à recuperação ambiental (ARALDI et al., 2006).

Nesse sentido, antes de proceder a implantação da espécie, ocorre a necessidade do conhecimento básico de algumas de suas características silviculturais, como por exemplo aquelas que são intrínsecas às sementes e que apresentam indiscutível importância na produção de mudas de qualidade. Essas características podem variar de região para região juntamente com os aspectos climáticos apresentados pelo ambiente onde estão localizadas as árvores matrizes selecionadas para a coleta das sementes.

A obtenção de informações como as supracitadas podem ser muito úteis na silvicultura da espécie, especialmente na fase de produção de mudas destinadas à restauração e/ou recuperação de áreas degradadas, ou mesmo para plantios destinados ao eventual aproveitamento madeireiro.

Neste contexto, tomando-se por base a carência de estudos básicos sobre a espécie e as promissoras características e possibilidade de uso apresentadas pela mesma, o presente estudo teve como objetivo determinar as características físicas e germinativas das sementes de catiguá-vermelho para a Região do Médio Alto Uruguai - RS, Brasil.

árvores matrizes localizadas em fragmentos de Floresta Estacional Decidual no Município de Frederico Westphalen - RS, Brasil. Após coletados, os frutos foram esparramados sobre sacos plásticos em local arejado e sombreado sob temperatura média de $25^{\circ} \mathrm{C}$ durante o 
período de 4 dias para perderem o excesso de umidade e assim facilitar a extração da casca e do arilo envolto nas sementes. Os aspectos dos frutos podem ser observados no conjunto de imagens apresentados na Figura 1.
A assepsia das sementes procedeu-se por meio da imersão em hipoclorito de sódio $(\mathrm{NaClO})$ a $2 \%$ por 1 minuto, seguida de lavagem em água corrente, tomando por base informações contidadas em Tambosi (2010) e Aimi (2016).
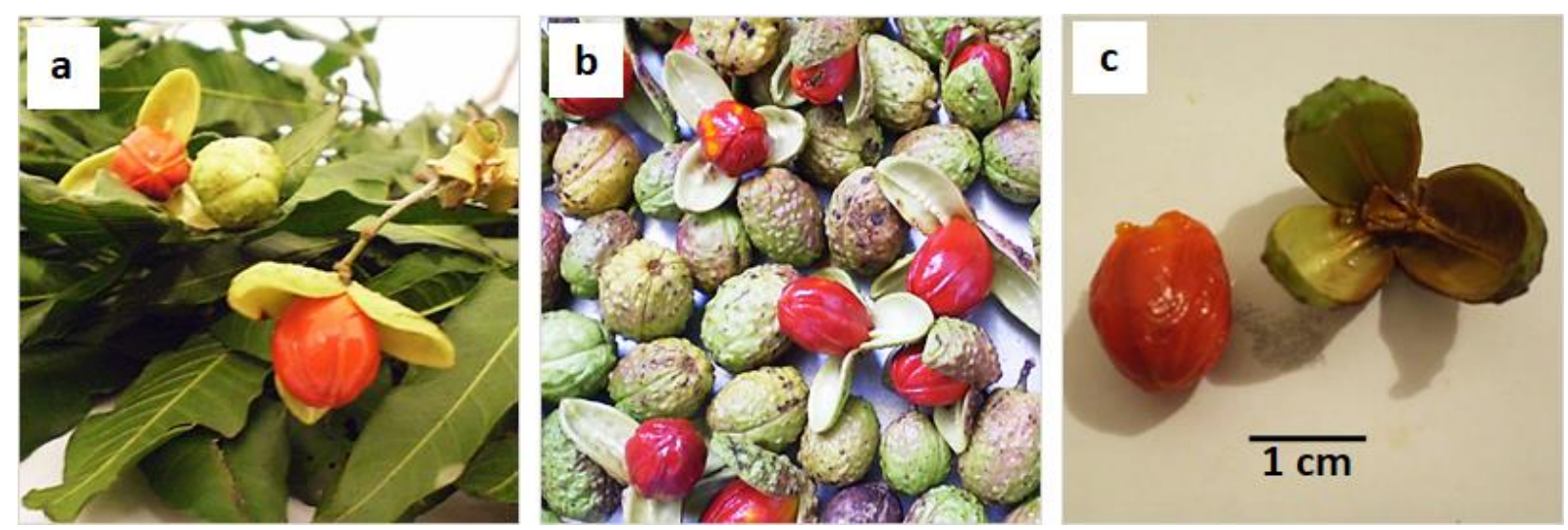

Figura 1. Aspectos gerais dos frutos de Trichilia claussenii. a) rutos e ramos imediatamente após a coleta; b) frutos três dias após a coleta; c) fruto com arilo e sua casca. Fonte: o Autor.

\section{Caracterização física das sementes}

Para a caracterização física do lote de sementes os testes descritos a seguir foram realizados seguindo os padrões descritos nas Regras de Análise de Sementes - RAS (BRASIL, 2009).

\section{a) Peso de mil sementes}

Foi realizada a contagem de oito amostras de 100 sementes, das quais foram calculados a variância $\left(\mathrm{S}^{2}\right)$, o desvio padrão (S) e o coeficiente de variação (CV\%).

Peso de mil sementes $=\frac{\text { peso da amostra. } 1000}{n^{\circ} \text { total de sementes }}$

De acordo com a RAS (BRASIL, 2009), quando o coeficiente de variação do peso de 1000 sementes fica abaixo de $4 \%$, mais 8 amostras devem adicionadas ao cálculo para diminuir a variabilidade das amostras. Esta medida deve ser realizada sucessivamente até que se alcance um CV $<$ que $4 \%$ para o lote.

\section{b) Número de sementes por quilograma}

Obtido através do cálculo regra de três a partir do resultado encontrado para o peso de mil sementes.

$$
\begin{aligned}
& 1000 \text { sementes }---\mathrm{x} \text { gramas } \\
& \text { x sementes }---1000 \text { gramas }
\end{aligned}
$$

\section{c) Teor de umidade}

Para esta determinação foram utilizadas 4 repetições de 25 sementes, onde cada repetição foi pesada inicialmente em condição úmida e logo após levadas até estufa de secagem sob temperatura de $105 \pm 3^{\circ} \mathrm{C}$ durante 24 horas.

Teor de umidade $(\%)=\frac{100(\mathrm{P}-\mathrm{p})}{\mathrm{P}-\mathrm{t}}$

Onde:

$\mathbf{P}$, é o peso inicial, ou seja, o peso do recipiente e sua tampa mais o peso da semente úmida; 
p, é o peso final, ou seja, o peso do recipiente e sua tampa mais o peso da semente seca;

t, é a tara, ou seja, o peso do recipiente com sua tampa.

\section{Variáveis avaliadas na germinação}

Para estas determinações foram utilizadas 16 repetições de 25 sementes, totalizando 400 sementes, as quais foram colocadas em caixas plásticas gerbox e umedecidas com água destilada (2,5 vezes o peso da vermiculita), após esses procedimentos as caixas plásticas gerbox foram encaminhadas para a câmara de germinação (BOD) sob fotoperíodo de 12 horas e temperatura constante de $25 \pm 2{ }^{\circ} \mathrm{C}$.

As avaliações de germinação foram efetuadas a cada 2 dias até o término do período de germinaçãoforam consideradas germinadas aquelas sementes que apresentaram comprimento de radícula maior que $2 \mathrm{~mm}$ (LABOURIAU \& VALADARES, 1976).

Após o término da germinação as seguintes variáveis foram analisadas:

\section{a) Índice de velocidade de germinação (IVG)}

Teste de vigor, calculado através da fórmula apresentada por Maguire (1962). Considera que quanto mais rápida for à germinação mais vigorosa é a semente, ou seja, é um índice que descreve o quão rápida é a germinação e que esta diretamente associado ao vigor ou

\section{RESULTADOS E DISCUSSÃO}

As sementes de catiguá-vermelho apresentaram um teor de umidade médio de $39,2 \%$, o que as caracteriza como recalcitrantes, conforme Bonner (2001). O mesmo autor ainda afirma que as sementes recalcitrantes, dependendo da espécie, não podem perder umidade entre 25 e $50 \%$, pois provavelmente perderão sua viabilidade. De acordo com Aguiar (1993), esse tipo de semente requer alto teor de capacidade germinativa das sementes (SANTANA \& RANAL, 2004). Muito utilizado para determinar a qualidade de lotes de sementes.

$$
\mathrm{IVG}=\frac{\mathrm{G} 1}{\mathrm{~N} 1}+\frac{\mathrm{G} 2}{\mathrm{~N} 2}+\ldots+\frac{\mathrm{Gn}}{\mathrm{Nn}}
$$

Onde:

G1, G2 e Gn = número de sementes germinadas computadas na primeira, na segunda e na última contagem;

N1, N2 e Nn = número de dias após semeadura na primeira, segunda e última contagem.

\section{b) germinação em função dos dias e germinação final}

Germinação em função dos dias é a porcentagem de germinação contabilizada em cada dia de leitura ou a cada 2 dias. Germinação final corresponde à porcentagem total de sementes germinadas contabilizadas no $14^{\circ}$ dia de germinação (último dia). Ambas as germinações foram determinadas através de regra de três (BRASIL, 2009).

\section{Análise dos dados}

A compilação dos dados, cálculos e análises estatísticas descritivas foram efetuados com auxílio do software MS Excel.

umidade para manter sua viabilidade por maior período de tempo.

$\mathrm{O}$ peso de mil sementes foi de $852 \mathrm{~g}$ com coeficiente de variação de $1,7 \%$, ficando abaixo de $4 \%$, valor este recomendado pelas Regras de Análise de Sementes (BRASIL, 2009). A quantidade de sementes estimada por quilograma foi de 1.175 sementes, valor mais baixo do que o reportado por Lorenzi (2002), que 
obteve o valor de 2.600 sementes $/ \mathrm{kg}$. Essa diferença entre as duas determinações pode ser explicada pelo teor de umidade distinto das sementes no momento em que foram submetidas à análise. Azeredo et al. (2003), acreditam que tais diferenças podem estar relacionadas as variações genético-ambientais entre as populaçõos utilizadas.

$\mathrm{Na}$ determinação do Índice Velocidade Germinação (IVG), o valor obtido foi de 2,78 , isto é, a velocidade com que as sementes de $T$. Claussenii germinaram a cada dois dias foi de 2,78. Já para o Tempo Médio de Germinação (TMG), o valor obtido foi de 7,7 dias, isto é, o número máximo de sementes germinadas está entre o $6^{\circ}(4,69)$ e $8^{\circ}$ $(4,13)$ dia conforme Tabela 1. Estabelecendo uma relação entre as duas variáveis, percebe-se que o TMG e o IVG encontram-se no intervalo do $8^{\circ}$ e $10^{\circ}$ dia, com uma taxa de germinação próxima aos 60,80\% (Tabela 1).

Quanto à germinação, esta demonstrou-se crescente até o $6^{\circ}$ dia, no qual apresentou o valor máximo de 4,69 sementes ou $18,76 \%$ do total. A partir daí, os valores foram decrescendo até atingirem a estabilidade no $14^{\circ}$ dia, no qual germinaram 1,56 sementes ou 6,24\% do total. Já na germinação final ou acumulada, o valor obtido foi de 18,32 sementes, as quais correspondem a 73,28\% de todas aquelas que foram postas para germinar. Visualizando este resultado final em uma aplicação prática, pode-se dizer a um viveirista que pretende semear mil sementes de catiguá-vermelho, considerando que estas apresentam características físicas semelhantes as que foram analisadas neste trabalho, e serão estabelecidas em um ambiente propício, aproximadamente 730 delas irão germinar.

Tabela 1. Frequências absolutas (fi) e relativas (fr\%) da germinação de Trichilia calussenii para a região do Médio Alto Uruguai, RS, Brasil.

\begin{tabular}{ccccc}
\hline Dias & $\mathrm{fi}$ & $\mathrm{fr}(\%)$ & fi (acum.) & fr (acum. \%) \\
\hline 2 & 0 & 0 & 0 & 0 \\
4 & 4,00 & 16,00 & 4,00 & 16,00 \\
6 & 4,69 & 18,76 & 8,69 & 34,76 \\
8 & 4,13 & 16,52 & 12,82 & 51,28 \\
10 & 2,38 & 9,52 & 15,20 & 60,80 \\
12 & 1,56 & 6,24 & 16,76 & 67,04 \\
14 & 1,56 & 6,24 & 18,32 & 73,28 \\
\hline Total & 18,32 & 73,28 & - & - \\
\hline
\end{tabular}

Conforme a Figura 2, a germinação da espécie iniciou no $4^{\circ}$ dia após a semeadura e o tempo necessário para a obtenção de aproximadamente $70 \%$ da germinação ficou entre o $12^{\circ}$ e $14^{\circ}$ dia após a semeadura. $\mathrm{O}$ que pode ser considerado um bom resultado uma vez as sementes da espécie não precisaram ser submetidas a nenhum tipo de tratamento pré-germinativo. 


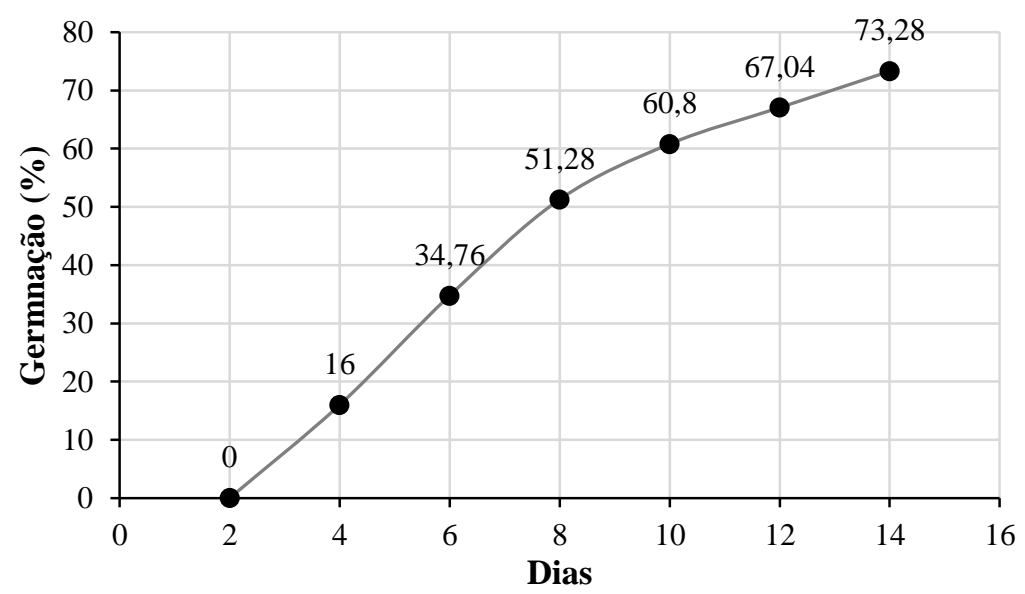

Figura 2. Germinação de sementes de Trichilia claussenii em função dos dias decorridos após a sua semeadura (Região do Médio Alto Uruguai, RS, Brasil).

\section{CONCLUSÃO}

Trichilia claussenii na Região do Médio Alto Uruguai-RS, apresenta aproximadamente 1.174 sementes/kg com teor de umidade de $39,2 \%$.

\section{REFERÊNCIAS}

AIMI, S. C.; ARAUJO, M. M.; MUNIZ, M. F. B.; WALKER, C. Teste de sanidade e germinação em sementes de Cabralea canjerana (Vell.) Mart. Ciência Florestal, Santa Maria, v. 26, n. 4, p. 1361-1370, 2016.

AGUIAR, I.B.; RODRIGUES, F.C.M.P.; FIGLIOLIA, M.B. 1993. Sementes Florestais Tropicais. Brasília: Associação Brasileira de Tecnologia de Sementes, 297 p., 1993.

ARALDI, D. B.; MELLO FILHO, J. A.; ARALDI, E. F.; SILVA, N. H. A. da. Contribuição ao Estudo do Catiguá (Trichilia claussenii C.DC.), no Rio Grande do Sul. Porto Alegre: FEPAGRO, Séries Técnicas Fepagro, n. 1, 2006.

AZEVEDO, M.R.Q.A; GOUVEIA, J.P.G.; TROVÃO, D.M.M.; QUEIROGA, V.P. Influência das embalagens e condições de armazenamento no vigor de sementes de gergelim. Revista Brasileira de Engenharia Agrícola e Ambiental, v.7, n. 3, p. 519-524, 2003.
As sementes apresentam 73,25\% de germinação, no final de 14 dias após a semeadura.

BONNER, F. T. Seed Biology. In: Woody-Plant Seed Manual. (s.1.): USDA Forest Service's/Reforestation, Nurseries, \& Genetics Resources, 2001.

BRASIL. Ministério da Agricultura, Pecuária e Abastecimento. Regras para análise de sementes. Brasília: MAPA/ACS, 399 p., 2009.

CORREA, P. M. . Dicionário de Plantas Úteis do Brasil. Rio de Janeiro: Ministério da Agricultura, v. 2, 1940.

GIRARDI, A. M. Contribuição ao Estudo da Nervação e Anatomia Foliar das Meliáceas do Rio Grande do Sul. II. Trichilia elegans JUSS. (Pau-de-ervilha). Boletim de la Sociedad Argentina de Botânica, Buenos Aires, v. 16, n. 3, p. 183-196, 1975.

LABOURIAU, L.G.; VALADARES, M.B. On the germination of seeds of Calotropis procera. An. Acad. Bras. Cienc., 48:174186, 1976. 
LONGHI, A. R. 1995. Livros das Árvores: Árvores e Arvoretas do Sul. Porto Alegre: L\&PM, p.65- 66, 1995.

LORENZI, H. Árvores Brasileiras: Manual de Identificação e Cultivo de Plantas Arbóreas Nativas do Brasil. Nova Odessa: Plantarum, p. 260, 2002.

MAGUIRE, J. D. Speed of germinationaid in selection and evaluation for seedling emergence and vigor. Crop Science, Madison, v. 2, n. 1, p. 176-177, 1962.

REITZ, R. As Plantas Meliáceas. Flora Ilustrada Catarinense, 1 Parte, Itajaí, 64 p., 1984.

SANTANA, D. G.; RANAL, M. A. Análise da germinação: um enforque estatístico. Brasília: Editora Universidade de Brasília, 248 p., 2004.

TAMBOSI, G.; RENNER, G. D. R. Avaliação de métodos de esterilização, concentração de ágar e composição de meio de cultura para propagação in vitro de Pimpinella anisum (Linn.) - Apiaceae. Semina, Londrin, v. 31, n. 2, p. 189-194, 2010 . 